\title{
Gaspar Mairal Buil. La Década del Riesgo. Situaciones y narrativas de riesgo en España a comienzos del siglo XXI. Investigación y debate. Madrid. Editorial Catarata. 2013 (189 páginas).
}

En una sociedad donde surgen noticias sobre riesgos y catástrofes de manera constante, la temática de riesgo ocupa un importante lugar como objeto de estudio en el campo de las ciencias sociales. Desde que Ulrich Beck publicara en 1986 La sociedad del riesgo ha surgido una importante línea de investigación en las ciencias sociales, que ha producido una gran cantidad de literatura científica a partir de la publicación de dicho libro.

La monografía que traemos a colación trata la temática del riesgo desde el análisis de la producción de narrativas de riesgo que afectan a la sociedad española contemporánea. La obra ha sido llevada a cabo gracias al grupo de estudio La sociedad del riesgo de la Universidad de Zaragoza y a la amplia experiencia investigadora del autor Gaspar Mairal en la línea de investigación tratada.

En esta obra se analizan las distintas narrativas de riesgo surgidas en la última década en España. Mairal desarrolla una teoría del riesgo que pueda ser aplicar de manera situacional, es decir, que sea válida para poder interpretar adecuadamente situaciones específicas de riesgo dentro de un contexto de construcción de narrativas de riesgo. Mairal enfoca el estudio del riesgo en base a su relación con la probabilidad de riesgo de un objeto dado y su construcción narrativa. La relación entre los dos objetos de riesgo sería la percepción de ese riesgo en base a construcciones narrativas creadas mediante el conocimiento previo de situaciones pasadas. Por ejemplo, la percepción del riesgo de tener un accidente de tráfico se produce cuando un individuo asocia un objeto de riesgo, como lo es la conducción de un vehículo, con otro objeto de riesgo, como lo es la salud o el conocimiento de anteriores accidentes de tráfico. Mediante las narrativas de riesgo se posibilita que la persona pueda asociar ambos objetos de manera probabilística. El autor se apoya en la filosofía de Paul Ricoeur para desarrollar la argumentación narrativa del riesgo. También se acoge a la definición de Gadamer sobre percepción para construir el concepto de percepción de riesgo y poder llegar a establecer una teoría donde se relacionen dos objetos de riesgo en base a su probabilidad de causar un daño. Para la operacionalización del concepto de riesgo recurre a las categorías de Luhmann sobre la diferencia entre riesgo y peligro.

Según Mairal, la concepción actual de riesgo proviene del concepto árabe rizq donde la persona religiosa confía en la providencia a modo de seguro divino. Una vez que se seculariza el concepto de riesgo empieza ser referido al transporte de mercancías. Esta secularización conceptual toma una nueva forma jurídica aplicada a los contratos de mercancías transportadas por mar como el quirad árabe o los contratos de commenda. "El riesgo es una estimación moderna que nació, entre otras investigaciones, gracias al uso de nuevos instrumentos de navegación" (p.113). El origen del riesgo es algo que forma parte de una jerga propia de expertos que queda materializado mediante una narración o cálculo respecto a una situación y una localización concreta. Por tanto, "el riesgo es tiempo y como tal un concepto acerca del futuro como probabilidad" (p.46). 
El libro ha sido distribuido en seis capítulos que pasamos a describir:

En el primer capítulo, el autor desarrolla una descripción de los principales acontecimientos que han producido narrativas de riesgo en la última década en España. En este sentido, hace referencia a las epidemias y los envenenamientos masivos como la gripe aviar, las vacas locas o los distintos brotes de legionella, pasando por las antenas de telefonía o los cultivos de alimentos transgénicos. También hace alusión a los desastres naturales, las catástrofes naturales, los no catastróficos (como los continuos accidentes de tráfico), los grandes riesgos medioambientales, la violencia y la inseguridad, las profesiones de riesgo, las conductas de riesgo (como es el caso de los deportes de riesgo), por último, reflexiona sobre el cálculo, la gestión y la prevención de riesgos.

En el segundo capítulo bajo la denominación Qué es el riesgo? realiza una abordaje conceptual del riesgo, donde se ofrece una teoría que pueda ser aplicada en distintas situaciones concretas de riesgo. También se ofrecen las distintas dimensiones del concepto de riesgo; riesgo definido como tiempo, conocimiento, relación y probabilidad.

El tercer capítulo titulado "Una sombra de riesgo en España: de la colza a las vacas locas". En él se definen y operacionalizan los principales conceptos tratados en la investigación: sociedad del riesgo, sombra de riesgo y matriz narrativa de riesgo. La definición de estos conceptos será fundamental para su aplicación teórica a determinados casos, que han producido narrativas de riesgo como el aceite de colza o las vacas locas.

El capítulo cuatro, Del riesgo al miedo: los accidentes de tráfico, se analiza la trayectoria de las historias de riesgo en la publicidad española, siendo las campañas de la Dirección General de Tráfico objeto central de tal análisis. Se realiza un minucioso análisis de contenido de las diferentes campañas publicitarias de la DGT y la manera en que su contenido ha ido cambiando a medida que se iba construyendo la narrativa de riesgo en torno a los accidentes de tráfico. En este sentido, se analiza la relación entre un objeto de riesgo: la conducción por carreteras y otro objeto de riesgo como lo es la salud y las consecuencias de los accidentes sobre ésta.

El quinto capítulo, que lleva por título Una matriz narrativa: el caso de la gripe aviar, se pone el acento en explicar en qué consiste una matriz narrativa de riesgo y cómo se producen en nuestra sociedad. Mairal relaciona el origen del periodismo con la creación de matrices de narrativa de riesgo "Las narrativas de riesgo están en el origen del sensacionalismo que, por otra parte, resultó fundamental en el desarrollo del periodismo" (p.119). Según el autor, en el periodismo estaría el origen de lo que se ha denominado matriz narrativa de riesgo, que consiste en una descripción de hechos establecidos que ayudan a interpretar la idea de la probabilidad de que tales situaciones puedan volver a ocurrir. En esta sección del texto, se analiza el caso de la gripe aviar de 1918 para establecer en qué medida la recreación de estos hechos han creado una matriz narrativa de riesgo que ha influido en la interpretación social del riesgo de un caso epidemia mucho posterior al mencionado, como es el de la gripe aviar producida en 2004. La referencia a la pandemia de 1918 y sus estragos estaban presentes en muchas de las noticias referidas a la alerta de riesgo en el caso de la gripe aviar de 2004. El mensaje del mecanismo de interpretación de una matriz de riesgo es el siguiente: "Lo que sucedió antes podría volver a repetirse" (p.125). El mecanismo consiste en localizar hechos pasado similares al que se quiere analizar y mediante comparación se establece la relación que ayude a interpretar situaciones 
presentes de riesgo. "La narratividad es finalmente la propiedad básica del riesgo, lo que le da carta de naturaleza como fenómeno cultural" (p.161).

El sexto y último capítulo que se titula El contexto narrativo: la catástrofe del Prestige. Ha sido escrito en cuarenta y cuatro páginas en las que el autor realiza un minucioso análisis del caso del accidente del buque petrolero Prestige ocurrido en 2002 frente a las costas gallegas. En este capítulo se define el contexto narrativo de riesgo como una estructura de tiempo dentro del que una acción tiene lugar. El objeto de análisis se centra en el desarrollo de la toma de decisiones que llevaron a alejar el petrolero de las costas españolas, facilitando su hundimiento. El autor piensa que dicha decisión no fue tomada dentro de un contexto de tipo científico, sino que en la decisión influyó una anterior matriz interpretativa de riesgo presente en la cultura local, a partir de anteriores catástrofes de hundimientos de otros petroleros frente a las costas gallegas. En última instancia, el temor de que se volvieran a repetir estos hechos hizo tomar la decisión de alejar el barco, frente a la toma de decisión proveniente de un conocimiento experto.

En resumen, Mairal presenta el riesgo como una fenomenología comunicacional, situacional y narrativa. El autor realiza un detallado análisis de distintas situaciones de riesgo y muestra como a partir de ellas se gestan las distintas narrativas de riesgo presentes en nuestra sociedad. También ofrece una teoría de tipo culturalista de la construcción del riesgo, pues las narrativas de riesgo no tienen que coincidir con el conocimiento experto, sino que han sido creadas culturalmente. "La construcción global del riesgo que se ha venido intensificando en la sociedad española no ha llegado todavía hasta el punto en el que un discurso de riesgo emerge con nitidez. Para que esto sea posible tendrán que surgir movimientos sociales capaces de construirlo de una forma global" (p.86).

Es de agradecer la llegada de esta nueva obra, que desde la antropología social posee un acertado diseño etnográfico aplicado al estudio de la producción de narrativas de riesgo. El trabajo posee un buen abordaje teórico, una clara conceptualización operativa y un adecuado diseño metodológico de tipo etnográfico, que permite analizar adecuadamente el objeto de estudio, así como realizar importantes reflexiones sobre las distintas narrativas de riesgo presentes en nuestra sociedad. Tal como comenta el autor: "[...] he querido abordar su investigación del modo más etnográfico posible, porque esto es lo que cada vez se echa más en falta en la abundante literatura que ya existe sobre el riesgo en las ciencias sociales. Hay una excesiva generalización que adolece de una base empírica sobre la que pueda sostenerse y en general más especulación que investigación cuidadosa" (p.18).

En definitiva, el riesgo es útil como herramienta de seguridad para gestionar actividades peligrosas y poder prevenir sus daños. En este sentido el autor presenta la gestión del riesgo como una herramienta fundamental para poder prevenir las inevitables situaciones de riesgo dentro de una sociedad que aplica principios científicos y racionales para su planificación, desarrollo y contingencia de las posibles situaciones de riesgo. 